\title{
Leadership Behaviors As Perceived By Pediatric Nurses and Its Effect on Their Satisfaction and Performance
}

\author{
Azza Abdel Moghny Attia* and Eman Saad Miligi** \\ *Pediatric Nursing Department, Faculty of Nursing, Cairo University, Egypt \\ ** Nursing Administration Department, Faculty of Nursing, Cairo University, Egypt
}

\begin{abstract}
Leadership behavior affects nurses' performance and satisfaction especially in high stressful environment such as the pediatric hospitals.

Aim: The study aimed to assess the leadership behaviors as perceived by pediatric nurses and its effect on their satisfaction and performance.

Methods: A descriptive correlational design is utilized for the current study, the study carried out in three settings Cairo University Specialized Pediatric Hospital, Egypt, Hail general hospital, and King Khalid general hospital, Ministry of Health, Kingdom of Saudi Arabia. Non-probability sampling; a purposeful sample of 126 nurses who fulfill the inclusion criteria. Three study tools were used to collect the study data Leader Behavior Description Questionnaire, Minnesota Satisfaction Questionnaire short form, and clinical performance rating scale, ethical considerations were ensured.

Results: results accept the study hypotheses that there is a positive correlation between perceived leadership behaviors (initiation and consideration), job satisfaction and performance among pediatric nurses, with highly statistically significant differences. Also there is a relationship between nurses' socio-demographic characteristics, perceived leadership behavior, job satisfaction and performance.

Conclusion, The perceived initiation and consideration behaviors positively influenced job satisfaction and performance of staff nurses working in pediatric hospitals, job satisfaction is higher among Egyptian, diploma and more than 5 years' experience nurses, while performance was higher among non-Egyptian and bachelor degree nurses with highly statistically significant differences. The study recommends that pediatric nurses need supportive environment from their supervisors and in-service training programs to enhance their performance.
\end{abstract}

Keywords: Job satisfaction, leadership behaviors, neonatal intensive care units, pediatric medical surgical wards, pediatric nurses, performance.

\section{Introduction}

Pediatric hospitals are known to be high stress workplace environments as the emotional impacts of seeing sick or dying children are often intensified. As nurses may experience overwhelming emotional stress, pain and sadness while working with sick or dying children and their families, they also need to develop specialized skills and abilities to handle the stressful situations ${ }^{[1]}$. Additionally, pediatric nurse demonstrates different roles as being responsible for making therapeutic relationship, family advocacy and caring, disease prevention and health promotion, health teaching, injury prevention, supporting and counseling, coordination and collaboration, ethical decision making, and to utilize researches and evidence based practice ${ }^{[2]}$. To attain these roles the nurses need protective, more conducive work environment, and effective leadership behavior. The need for job satisfaction for pediatric nurses to ensure high quality care was emphasized ${ }^{[3]}$.

Job satisfaction refers to a pleasant or positive emotional condition, which is derived from an employee's appreciation for his/ her occupation or work experience. Research results have shown that organizational behaviors, like warmth among employees, mutual trust, respect and rapport between employees and superiors can be significant predicting factors of the job satisfaction experienced by employees ${ }^{[4]}$.

Effective leadership has a significant impact on the quality of care, ensuring patient safety and facilitating positive staff development ${ }^{[5]}$. Nurse performance is vital to quality patient care, and the effective leadership is associated with optimal hospital performance ${ }^{[6]}$. Corollary to this, it is also essential in determining nurses' level of job satisfaction and their performance which is a long-standing concern in pediatric hospitals as well as related to their job satisfaction ${ }^{[7]}$.

Leadership is the process of influencing a group of individuals to achieve shared objectives ${ }^{[8]}$ Moreover, leadership described as a capability to influence the performance of followers ${ }^{[9]}$. In addition to that, leadership defined as an influence relationship among leaders and followers who intend real changes and outcomes thus reflecting on their satisfaction and performance ${ }^{[10]}$. While on the other hand Ohio State University Studies ${ }^{[11]}$, clarified two leadership styles which are the consideration and the initiating structure. These were defined as consideration which is people oriented behavioral leaders and initiating structure is task oriented leaders. 
Consideration is defined as behaviors by means the leader establish rapport with the nurses, two-way communication, mutual respect, and understanding. It includes behavior indicating trust and warmth between the leader and her staff and emphasizes concern for group members' needs. In contrast, initiating structure is defined as behaviors by means of which the leader defines or facilitates group interaction toward goal attainment. The leader does this by planning, scheduling, criticizing, initiating ideas, organizing the work, defining member roles, assigning tasks, and pushing for production ${ }^{[12]}$.

The research findings emphasized when leaders were perceived as providing minimal support to pediatric nurses work performance declined, and job dissatisfaction increased ${ }^{[13]}$. Henceforth, it can be gleaned from the stated findings that pediatric nurses' perceptions of leaders support were vital to their job performance and increasing satisfaction on the workplace. In this respect, leadership behaviors of head nurse greatly influenced the job satisfaction and performance among nurses in pediatric hospitals ${ }^{[14]}$.

Studies were reported about factors affecting the job satisfaction and performance among nurses generally, but little is known about the leadership behaviors as perceived by pediatric nurses and its effect on their satisfaction and performance in various pediatric settings especially in pediatric wards, there is a gap in knowledge in this area. Also the relationship between demographic variables, job satisfaction and performance among pediatric nurses are understudied.

\subsection{Aim of the Study:}

The aim of the current study was to assess the leadership behaviors as perceived by pediatric nurses and its effect on their satisfaction and performance

\subsection{Hypotheses:}

1.2.1 There is a positive correlation between perceived leadership behaviors and pediatric nurses' job satisfaction.

1.2.2 There is a positive correlation between perceived leadership behaviors and pediatric nurses' performance.

1.2.3 There is a relationship between nurses' socio-demographic characteristics, perceived leadership behaviors, job satisfaction and performance.

\subsection{Operational definitions:}

A leadership behaviors consists of consideration and initiation behavior:

Consideration behavior: The leader act in friendly and supportive manner shows concern for subordinates and looks out for their welfare.

Initiation behavior: Leader defines and structures her role and the roles of subordinates toward attainment of the groups' formal goals.

\section{Methods}

\subsection{Design}

A descriptive correlational design is utilized for the current study; to detect if there is a relationship between the quantitative variables from the same group of subjects.

\subsection{Setting of data collection:}

The present study was conducted in three settings:

2.2.1 Medical and surgical departments Cairo University Specialized Pediatric Hospital (CUSPH), Egypt.

2.2.2 Neonatal intensive care unit and pediatric medical surgical department, Hail general hospital, Ministry of health, Kingdom of Saudi Arabia.

2.2.3 Neonatal intensive care unit and pediatric medical surgical department, King Khalid general hospital, Ministry of health, Kingdom of Saudi Arabia

\subsection{Sample:}

Non-probability sampling; a purposeful sample of 126 nurses who satisfy the preset inclusion criteria.

Inclusion criteria of pediatric nurses:

-Have at least 2 years of experience in pediatric settings.

-Working in neonatal intensive care units, pediatric medical and surgical departments.

- Accept to be included in the study.

All nurses who satisfy the previous criteria were the study sample. Thirty nurses were recruited from Egypt and 96 from Kingdom of Saudi Arabia (71 Filipinos, 13 Indian and 12 Saudi) for the purpose of the study. The variation in nationalities of the sample of Saudi Arabia nurses due to the multi nationalities of nurses working in Saudi hospitals. In spite of the confidentiality of the study data many nurses in Egypt refuse to participate in the study when know their performance were assessed especially in NICU. 
2.4 Date collection tools: (Self-administered tools by the nurses included in the study):

2.4.1 Nurses' Socio-demographic data sheet: including nurses' qualification, years of experience, nationality, and work department

2.4.2 Leader Behavior Description Questionnaire (LBDQ) ${ }^{[11][15]}$; the tool consists of 40 items to be answered, for each item from 1-40 the staff nurse should think about how frequently the leader engages in the behavior described by the item, five levels are available to choose one of them (always=A, often=B, occasionally $=\mathrm{C}$, seldom $=\mathrm{D}$ or never $=\mathrm{E}$ )

\section{Scoring system of LBDQ:}

The items were rated on a five-point scale scored at follows

Always $=5 ;$ Often $=4 ;$ Occasionally $=3 ;$ Seldom $=2 ;$ Never $=1$.

Only 30 of the 40 items are scored; 15 for each of the two behaviors (initiation and consideration). The 10 unscored items have been retained in the questionnaire in order to keep the conditions of administration comparable to those used in standardizing the questionnaire. Total score of initiation and consideration structure are 75 score for each, low initiation and consideration are considered at score equal to less than 50 .

2.4.3 Minnesota Satisfaction Questionnaire (MSQ) Short Form includes 20 questions ${ }^{[16]}$

\section{There are 5 rating scales that include:}

$\begin{array}{ll}5=\text { Extremely Satisfied } & 4=\text { Very Satisfied } \\ 3=\text { Satisfied } & 2=\text { Somewhat Satisfied }\end{array}$

$1=$ Not Satisfied

\section{Scoring system:}

The total score of MSQ is one hundred; score 75 or higher would present higher degree of satisfaction, 25 or lower would indicate a low level of satisfaction, and scores in the middle range indicate average satisfaction.

2.4.4 Clinical performance rating scale (CPRS) (Evaluation done by the researchers) the items adapted from ${ }^{[2]}$ the tool developed by the researchers in English including sixteen items including: e.g. developing nursing care plan, communication skills, teaching parent and child, demonstrate self- awareness, carryout responsibilities and be accountable, exhibit caring behavior, demonstrate leadership abilities, exhibit critical thinking and professional conduct.

Scoring system of CPRS:

Each response is weighted, the score ranged between "0-4". The highest score reflects the proper performance of the nurses. The total scores were 64 . The adequate performance allotted score $60 \%$ and more and inadequate equal less than $60 \%$

Validity of study tools:

Leader Behavior Description Questionnaire (LBDQ) ${ }^{[11][15]}$, and Minnesota Satisfaction Questionnaire (MSQ) Short Form ${ }^{[16]}$; translated into Arabic language, the content validity was tested by a jury consisted of 3 professors and experts in nursing administration and pediatric nursing to ascertain that the tools was relevant, understood, and applicable; the necessary modifications were carried accordingly, also validity of clinical performance rating scale (CPRS) content was evaluated to ensure its content validity.

\section{Reliability of the tools:}

- The estimated reliability of LBDQ by the split-half method is .83 for the initiating structure scores, and .92 for the consideration scores.

- The estimated reliability of MCQ is .90 for general satisfaction.

- Reliability of the CPRS was tested by using Cronbach's Alpha; the alpha obtained was 0.756, indicating a high degree of internal consistency.

\subsection{Pilot study:}

A pilot study was carried out to test the validity, practicability and applicability of the tools. Leader behavior description questionnaire, Minnesota satisfaction questionnaire short form and clinical performance rating scale were applied on 5 nurses in Egypt and 10 in Saudi Arabia. Time needed to complete the first two tools was less than half an hour. Minor modifications were done on (CPRS) based on the findings obtained from the pilot study. Nurses of the pilot study were included among the study sample.

\subsection{Ethical considerations:}

Written consent will be obtained from nurses participated in the study after complete description of study benefits and risks, confidentiality of the data will be assured and voluntary participation, the right of nurses to withdrawal from the study at any time assured also. 
Leadership Behaviors As Perceived By Pediatric Nurses and Its Effect on Their Satisfaction and ..

\subsection{Procedure:}

- Initial approval attained from the research ethical committee in Faculty of Nursing Cairo-University in Egypt and Hail University in Kingdom of Saudi Arabia.

- An official permission will be obtained from the directors of previous mentioned settings, as well as permission from the heads of pediatric departments (medicine and surgery), and neonatal intensive care units.

- The researchers introduced themselves to nurses of the study sample, then explained the purpose of the study and obtained their written consent to participate in the study.

- LBDQ and MSQ were translated into Arabic, the content validity was assured to ascertain that the tools were relevant, understood, and applicable; the necessary modifications were carried accordingly.

- A pilot study was done on 15 nurses to evaluate the feasibility and applicability of the tools.

- LBDQ and MSQ were self-administered tool by the nurses either in Arabic for Arab nurses or in English for foreigner nurses within an average time of 20-30 minutes

- Each nurse was individually observed during her clinical work by the researchers to fulfill the clinical performance rating scale at least after 3 times observation and the mean of the three times is taken.

\subsection{Statistical analysis:}

Data were summarized, tabulated, and presented using descriptive statistics in the form of frequency distribution, percentages, arithmetic means and standard deviations were done using SPSS 20.0. Qualitative categorical variables were compared using chi-square test. The nonparametric Mann-Whitney test is used to compare difference between the population medians. Pearson correlation analysis was used for assessment of the inter-relationships among quantitative variables. Statistical significance was considered at p-value $<0.05$.

\section{Results}

Table 1: Socio-demographic characteristics of pediatric nurses $\quad(n=126)$

\begin{tabular}{|c|c|c|}
\hline & Frequency & Percent \\
\hline \multicolumn{3}{|l|}{ Nationality: } \\
\hline Egyptian & 30 & 23.9 \\
\hline Indian & 13 & 10.3 \\
\hline Filipino & 71 & 56.3 \\
\hline Saudi & 12 & 9.5 \\
\hline \multicolumn{3}{|l|}{ Nationality: } \\
\hline Egyptian & 30 & 23.8 \\
\hline Non-Egyptian & 96 & 76.2 \\
\hline \multicolumn{3}{|l|}{ Department: } \\
\hline NICUs & 65 & 51.6 \\
\hline Wards & 61 & 48.4 \\
\hline \multicolumn{3}{|c|}{ Experience years: } \\
\hline$<5$ & 56 & 44.4 \\
\hline $5+$ & 70 & 55.6 \\
\hline Range & \multicolumn{2}{|c|}{$1.0-24.0$} \\
\hline Mean \pm SD & \multicolumn{2}{|c|}{$4.6 \pm 0.5$} \\
\hline Median & \multicolumn{2}{|c|}{5.00} \\
\hline \multicolumn{3}{|c|}{ Nursing qualification: } \\
\hline Bachelor & 80 & 63.5 \\
\hline Diploma & 46 & 36.5 \\
\hline
\end{tabular}

Table (1) reveals that $76.2 \%$ of pediatric nurses are non-Egyptian; $56.3 \%$ of them are Filipino followed by $23.8 \%$ are Egyptian nationality, nurses working at neonatal intensive care units are $51.6 \%$ while the rest of the nurses working in pediatric wards $48.4 \%$, regarding years of experience $55.6 \%$ having more than 5 years of experience in working with children and $63.5 \%$ of the total sample have bachelor degree in nursing.

Table 2: Mean scores of perceived consideration and initiation behaviors, job satisfaction, and performance among pediatric nurses $(\mathrm{n}=126)$

\begin{tabular}{|l|c|c|c|c|}
\hline & Range & Mean \pm SD & Median & $1^{\text {st }}-3^{\text {rd }}$ quartiles \\
\hline Consideration (max.=75) & $24.0-75.0$ & $53.4 \pm 10.7$ & 55.00 & $46.0-60.0$ \\
\hline Initiation (max.=75) & $27.0-75.0$ & $59.1 \pm 10.9$ & 60.00 & $54.0-67.0$ \\
\hline Job satisfaction (max.=100) & $34.0-100.0$ & $68.9 \pm 17.1$ & 70.00 & $56.0-80.0$ \\
\hline Performance (max.=64) & $13.0-64.0$ & $47.0 \pm 15.7$ & 56.00 & $33.0-61.0$ \\
\hline
\end{tabular}

Table (2) shows that the mean scores of perceived leadership behaviors (consideration and initiation) among pediatric nurses are $53.4 \pm 10.7$ and $59.1 \pm 10.9$ respectively. The mean score of job satisfaction is $68.9 \pm 17.1$ and nurses' performance mean score is $47.0 \pm 15.7$. 
Leadership Behaviors As Perceived By Pediatric Nurses and Its Effect on Their Satisfaction and ..

Table 3: Percentage distribution of perceived consideration and initiation behaviors, job satisfaction, and performance levels among pediatric nurses in the study sample $(n=126)$

\begin{tabular}{|l|c|c|}
\hline & \multicolumn{2}{|c|}{ Frequency } \\
\hline Job satisfaction: & 21 & 16.7 \\
\hline Low (25 score and less) & 54 & 42.9 \\
\hline Average (26-74 score) & 51 & 40.5 \\
\hline High (75 score and more) & \multicolumn{2}{|c|}{} \\
\hline Consideration: & 6 & 4.8 \\
\hline Low (less than 50) & 120 & 95.2 \\
\hline High (more than 50) & 6 & 4.8 \\
\hline Initiation: & 120 & 95.2 \\
\hline Low (less than 50) & \multicolumn{2}{|c|}{} \\
\hline High (more than 50) & 84 & 66.7 \\
\hline Performance: & 42 & 33.3 \\
\hline Inadequate (less than 60 \%) & \multicolumn{2}{|c|}{} \\
\hline Adequate (60\% and more) & \multicolumn{2}{|c|}{} \\
\hline
\end{tabular}

Table (3) illustrates that $42.9 \%$ followed by $40.5 \%$ of pediatric nurses have average and high job satisfaction scores, $95.2 \%$ have high consideration and initiation scores, while only $33.3 \%$ have adequate performance score.

Table 4: Relations between pediatric nurses' scores of perceived consideration behavior and their characteristics $(\mathrm{n}=126)$

\begin{tabular}{|c|c|c|c|c|}
\hline & \multicolumn{2}{|c|}{ Consideration score/75 } & \multirow{2}{*}{$\begin{array}{c}\text { Mann- } \\
\text { Whitney test }\end{array}$} & \multirow{2}{*}{ p-value } \\
\hline & Mean \pm SD & Median & & \\
\hline $\begin{array}{l}\text { Nationality: } \\
\text { Egyptian } \\
\text { Non-Egyptian }\end{array}$ & $\begin{array}{c}45.3 \pm 10.7 \\
56.0 \pm 9.4 \\
\end{array}$ & $\begin{array}{c}46.00 \\
55.0 \\
\end{array}$ & 21.40 & $<0.001 *$ \\
\hline $\begin{array}{l}\text { Department: } \\
\text { NICUs } \\
\text { Wards } \\
\end{array}$ & $\begin{array}{l}53.3 \pm 10.8 \\
53.6 \pm 10.7 \\
\end{array}$ & $\begin{array}{l}53.00 \\
55.00 \\
\end{array}$ & 0.57 & 0.45 \\
\hline $\begin{array}{l}\text { Experience years: } \\
<5 \\
5+\end{array}$ & $\begin{array}{l}52.0 \pm 10.0 \\
54.6 \pm 11.2 \\
\end{array}$ & $\begin{array}{l}53.00 \\
55.00 \\
\end{array}$ & 2.99 & 0.08 \\
\hline $\begin{array}{l}\text { Nursing qualification: } \\
\text { Bachelor } \\
\text { Diploma }\end{array}$ & $\begin{array}{c}55.4 \pm 9.0 \\
49.9 \pm 12.5\end{array}$ & $\begin{array}{l}55.00 \\
49.00\end{array}$ & 8.44 & $0.004 *$ \\
\hline
\end{tabular}

(*) Statistically significant at $p<0.05$

Table (4) shows that high mean scores of perceived consideration behavior are detected among non-Egyptian nurses and bachelor degree nurses with highly statistically significant differences. No statistically significant differences in relation to work settings and years of experience.

Table 5: Relations between pediatric nurses' scores of perceived initiation behavior and their characteristics $(n=126)$

\begin{tabular}{|c|c|c|c|c|}
\hline & \multicolumn{2}{|l|}{ Initiation score/75 } & \multirow{2}{*}{$\begin{array}{l}\text { Mann- } \\
\text { Whitney test }\end{array}$} & \multirow{2}{*}{$\mathrm{p}$-value } \\
\hline & Mean \pm SD & Median & & \\
\hline $\begin{array}{l}\text { Nationality: } \\
\text { Egyptian } \\
\text { Non-Egyptian }\end{array}$ & $\begin{array}{c}47.2 \pm 10.7 \\
62.8 \pm 7.8\end{array}$ & $\begin{array}{l}50.50 \\
63.50\end{array}$ & 41.72 & $<0.001 *$ \\
\hline $\begin{array}{l}\text { Department: } \\
\text { NICUs } \\
\text { Wards } \\
\end{array}$ & $\begin{array}{l}59.8 \pm 10.1 \\
58.3 \pm 11.6\end{array}$ & $\begin{array}{l}60.00 \\
60.00 \\
\end{array}$ & 0.08 & 0.78 \\
\hline $\begin{array}{l}\text { Experience years: } \\
<5 \\
5+\end{array}$ & $\begin{array}{l}58.5 \pm 11.1 \\
59.6 \pm 10.7\end{array}$ & $\begin{array}{l}59.00 \\
60.50\end{array}$ & 0.40 & 0.53 \\
\hline $\begin{array}{l}\text { Nursing qualification: } \\
\text { Bachelor } \\
\text { Diploma }\end{array}$ & $\begin{array}{c}62.2 \pm 7.8 \\
53.8 \pm 13.2\end{array}$ & $\begin{array}{l}62.50 \\
55.50\end{array}$ & 13.86 & $<0.001 *$ \\
\hline
\end{tabular}

(*) Statistically significant at $p<0.05$

Table (5) shows that high mean scores of perceived initiation behavior are detected among non-Egyptian nurses and bachelor degree nurses with highly statistically significant differences. No statistically significant differences in relation to work settings and years of experience. 
Leadership Behaviors As Perceived By Pediatric Nurses and Its Effect on Their Satisfaction and ..

Table 6: Relations between pediatric nurses' scores of job satisfaction and their characteristics $(\mathrm{n}=126)$

\begin{tabular}{|c|c|c|c|c|}
\hline & \multicolumn{2}{|c|}{ Job satisfaction score/100 } & \multirow{2}{*}{$\begin{array}{c}\text { Mann- } \\
\text { Whitney test }\end{array}$} & \multirow{2}{*}{ p-value } \\
\hline & Mean \pm SD & Median & & \\
\hline $\begin{array}{l}\text { Nationality: } \\
\text { Egyptian } \\
\text { Non-Egyptian }\end{array}$ & $90.7 \pm 3.9$ & 90.00 & 6030 & 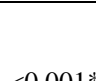 \\
\hline $\begin{array}{l}\text { Department: } \\
\text { NICUs } \\
\text { Wards }\end{array}$ & $\begin{array}{l}62.3 \pm 15.8 \\
61.8 \pm 22.2\end{array}$ & $\begin{array}{l}60.00 \\
63.00\end{array}$ & 0.37 & 0.54 \\
\hline $\begin{array}{l}\text { Experience years: } \\
<5 \\
5+\end{array}$ & $\begin{array}{l}59.3 \pm 20.5 \\
64.3 \pm 17.8\end{array}$ & $\begin{array}{l}57.50 \\
62.00\end{array}$ & 4.62 & $0.03 *$ \\
\hline $\begin{array}{l}\text { Nursing qualification: } \\
\text { Bachelor } \\
\text { Diploma }\end{array}$ & $\begin{array}{l}54.3 \pm 13.1 \\
75.6 \pm 20.4\end{array}$ & $\begin{array}{l}59.00 \\
87.50\end{array}$ & 27.79 & $<0.001^{*}$ \\
\hline
\end{tabular}

(*) Statistically significant at $p<0.05$

Table (6) indicates the Egyptian pediatric nurses have high mean satisfaction scores $(90.7 \pm 3.9)$ than non-Egyptian, also for diploma nurses they have high mean satisfaction scores $(75.6 \pm 20.4)$ than bachelor degree nurses with highly statistically significant differences, the nurses have more than 5 years of experience more satisfied than less than 5 years of experience nurses with statistically significant difference. No statistically significant difference is detected in satisfaction score between NICU and departments nurses.

Table 7: Relations between nurses' scores of performance and their characteristics $(n=126)$

\begin{tabular}{|c|c|c|c|c|}
\hline & \multicolumn{2}{|c|}{ Performance score/ 64} & \multirow{2}{*}{$\begin{array}{c}\text { Mann- } \\
\text { Whitney test }\end{array}$} & \multirow{2}{*}{ p-value } \\
\hline & Mean \pm SD & Median & & \\
\hline $\begin{array}{l}\text { Nationality: } \\
\text { Egyptian } \\
\text { Non-Egyptian }\end{array}$ & $\begin{array}{c}45.3 \pm 10.7 \\
56.0 \pm 9.4\end{array}$ & $\begin{array}{c}46.00 \\
55.0\end{array}$ & 21.40 & $<0.001^{*}$ \\
\hline $\begin{array}{l}\text { Department: } \\
\text { NICUs } \\
\text { Wards }\end{array}$ & $\begin{array}{l}53.3 \pm 10.8 \\
53.6 \pm 10.7\end{array}$ & $\begin{array}{l}53.00 \\
55.00\end{array}$ & 0.57 & 0.45 \\
\hline $\begin{array}{l}\text { Experience years: } \\
<5 \\
5+\end{array}$ & $\begin{array}{l}52.0 \pm 10.0 \\
54.6 \pm 11.2\end{array}$ & $\begin{array}{l}53.00 \\
55.00 \\
\end{array}$ & 2.99 & 0.08 \\
\hline $\begin{array}{l}\text { Nursing qualification: } \\
\text { Bachelor } \\
\text { Diploma }\end{array}$ & $\begin{array}{c}55.4 \pm 9.0 \\
49.9 \pm 12.5\end{array}$ & $\begin{array}{l}55.00 \\
49.00\end{array}$ & 8.44 & $0.004 *$ \\
\hline
\end{tabular}

(*) Statistically significant at $p<0.05$

Table (7) reveals that non-Egyptian and bachelor degree nurses have higher mean scores of

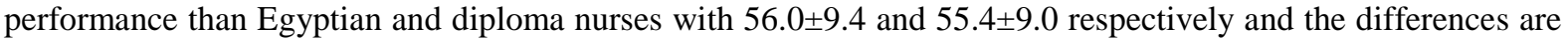
highly statistically significant. The settings of work do not affect the nurses' performance but the nurses with more than 5 years of experience slightly their mean scores of performance are improved but not reach the threshold of statistically significant difference.

Table 8: Relations between nurses' scores of consideration, job satisfaction and performance $(\mathrm{n}=126)$

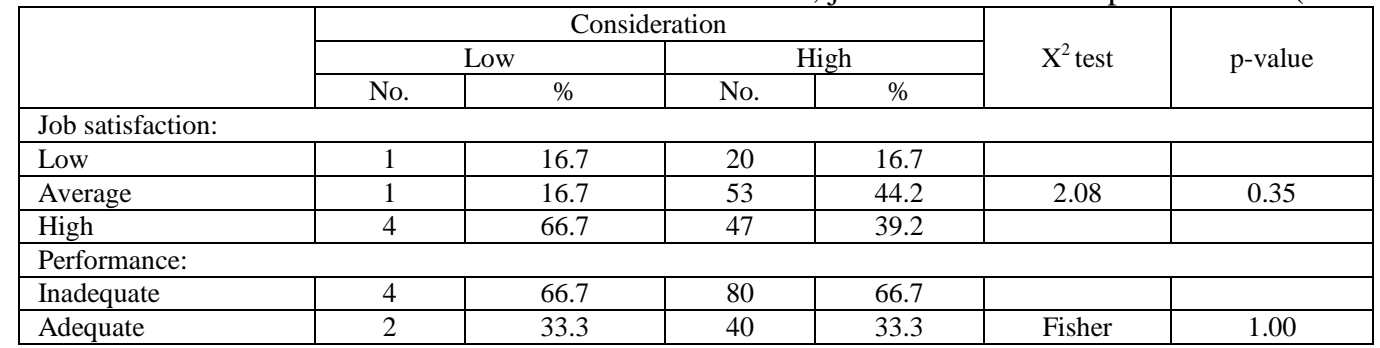

(*) Statistically significant at $p<0.05$

Table (8) shows that majority of nurses who have high consideration score $44.2 \%$ followed by $39.2 \%$ have average and high job satisfaction respectively. While only half of nurses have high consideration score have adequate performance $33.3 \%$. No significant differences are detected. 
Leadership Behaviors As Perceived By Pediatric Nurses and Its Effect on Their Satisfaction and ..

Table 9: Relations between nurses' scores of initiation, job satisfaction and performance $(\mathrm{n}=126)$

\begin{tabular}{|c|c|c|c|c|c|c|}
\hline & \multicolumn{4}{|c|}{ Initiation } & \multirow{3}{*}{$\mathrm{X} 2$ test } & \multirow{3}{*}{ p-value } \\
\hline & \multicolumn{2}{|c|}{ Low } & \multicolumn{2}{|c|}{ High } & & \\
\hline & No. & $\%$ & No. & $\%$ & & \\
\hline \multicolumn{7}{|c|}{ Job satisfaction: } \\
\hline Low & 0 & 0.0 & 21 & 17.5 & & \\
\hline Average & 3 & 50.0 & 51 & 42.5 & 1.27 & 0.53 \\
\hline High & 3 & 50.0 & 48 & 40.0 & & \\
\hline \multicolumn{7}{|c|}{ Performance: } \\
\hline Inadequate & 6 & 100.0 & 78 & 65.0 & & \\
\hline Adequate & 0 & 0.0 & 42 & 35.0 & Fisher & 0.18 \\
\hline
\end{tabular}

(*) Statistically significant at $p<0.05$

Table (9) illustrates the nurses with high initiation score $42.5 \%$ followed by $40 \%$ have average and high job satisfaction respectively; all nurses have adequate performance have high score of initiation $35 \%$.

Table 10: Correlation of nurses scores of job satisfaction, performance, consideration and initiation, and their qualification and experience

\begin{tabular}{|c|c|c|c|c|}
\hline & \multicolumn{4}{|c|}{ Spearman's rank correlation coefficient } \\
\hline & Consideration & Initiation & Satisfaction & Performance \\
\hline Consideration & & & & \\
\hline Initiation & $.707 * *$ & & & \\
\hline Job satisfaction & $.285 * *$ & $.290 * *$ & & \\
\hline Performance & $.362 * *$ & $.371 * *$ & 0.09 & \\
\hline Experience & $.175^{*}$ & .081 & -.006 & $.272 * *$ \\
\hline Qualification & $-.260 * *$ & $-.333 * *$ & -.060 & $.468 *$ \\
\hline
\end{tabular}

(*) Statistically significant at $p<0.05$

(**) Statistically significant at $p<0.01$

Table (10) reveals that strong positive correlation .707 is detected between perceived initiation and consideration behaviors by pediatric nurses; positive correlation is detected between perceived initiation and consideration behaviors and job satisfaction and performance among pediatric nurses. There is positive correlation between nurses' qualification and performance .468 , but negative correlation is detected between perceived initiation and consideration behaviors, satisfaction and nurses' qualifications.

\section{Discussion}

Leadership behaviors play a crucial role in the satisfaction and performance of staff nurses. Moreover, leadership behaviors as perceived by the pediatric nurses made the work environment more conducive to work effectively and high job satisfaction. Therefore, the current study, aimed to assess the leadership behaviors as perceived by pediatric nurses and its effect on their satisfaction and performance.

The study results revealed that the pediatric nurses perceive the initiation behavior of their leaders more than consideration, this result in accordance with Platis et al., who proved that the style of initiation make the nurses more focused, structured, keep them on the right track, knew in advance what is expected from them rather than building good relationship with their leaders all these behaviors are closely associated with job satisfaction which indicated to high job performance.

The study results accept the first hypothesis that: There is a positive correlation between perceived leadership behaviors (initiation and consideration) by pediatric nurses and their job satisfaction with highly statistically significant difference. These findings consistent with Al-Ahmadi who reported that nurses who perceive their head nurses to be supportive are more likely satisfied. The study results confirm the results reported by Said et al., (2015) titled the quality of working life among nurses in pediatric setting in Portugal conclude that supportiveness of leadership promotes positive job outcomes, in other words improving working conditions in the hospitals is important to maintain high-quality care and nurses' job satisfaction.

Consistent with prior researches which indicated that average satisfaction were detected among the total study sample ${ }^{[17][20]}$. Only about one third of the total sample have adequate performance among pediatric nurses as being evaluated by the researchers but another researches assess the nurses performance through selfrating by nurses themselves which may raise the subjectivity and some researchers write that as limitations of their study ${ }^{[18]}$.

Second hypotheses: The current study results accept that there is positive correlation was detected between perceived leadership behaviors (initiation and consideration) by pediatric nurses and their performance with highly statistically significant difference. Consistent with previous researches done by Hairr et al., which emphasize the role of leadership in establishment of best practice working conditions and the work of Salanova et al., that support the leadership behavior have positive effect on nurses performance. Empirically, research 
confirms that consideration leadership behavior display unique relations with a variety of important outcomes including group performance and satisfaction with one's leader ${ }^{[23]}$.

Third hypotheses: The study results proved that a relationship between nurses' socio-demographic characteristics, perceived leadership behavior, job satisfaction and performance are existed. Perceived consideration and initiation behaviors are higher among non-Egyptian nurses and bachelor degree nurses with highly statistically significant differences, these results not congruent with results of study done in Egypt entitled " work motivating factors as identified by diploma nurses in children hospital at Elmonira and Specialized Pediatric hospital, Cairo University" which concluded supervision, guidance and protective attitude in the different work situations were perceived by the nurses as the highly motivating factors ${ }^{[24]}$.

The study results revealed that non-Egyptian nurses and bachelor degree nurses have higher performance score, from the researchers point of view more than two thirds of pediatric nurses are foreigner and working in Saudi Arabia and they wish to renewal their contract because the advantages of high salary than their countries also their place of work has a system and well prepared infra-structure, added to that they have to follow the instructions provided by their supervisors blindly.

The results of the current study illustrates that the Egyptian pediatric nurses have high mean satisfaction scores $(90.7 \pm 3.9)$ than non-Egyptian, from the researchers point of view the Egyptian nurses have stable work environment in spite of the daily challenges meet them during caring for sick children but their work is appreciated by their supervisors and medical team, this view is supported by Belias and Koustelios which mentioned in organizations which are flexible and adopt the participative management type, with emphasis in communication and employees' reward, the latter are more likely to be satisfied. Also diploma nurses they have high mean satisfaction scores $(75.6 \pm 20.4)$ than bachelor degree nurses with highly statistically significant differences, these results in accordance with the study done by Said et al., 2013. This may be due to the bachelor degree nurses working as bedside nurse in NICUs, which may affect their self-esteem and selfrecognition.

The study results revealed that more experience nurses more satisfied than nurses have less years of experience this in accordance with Said et al., (2015) who illustrate older nurses with more years of experience and more years at the hospital had fewer jobs stress than their younger counterparts. Also Ernst et al., reported that nurses with more years of experience, longevity on the unit and at the hospital had more confidence, showed less concern about time demands. Older nurses were more satisfied with recognition they received than their younger nurses. As well as these years of experience mature them with clinical experience, ability to lead, integrity to grow and foster advancement and adjustment with others.

Also the study findings indicating that no statistically significant difference between NICU and pediatric medical and surgical department nurses satisfaction, these results not in accordance with Said et al., (2015) which concluded the general pediatric departments have more satisfaction than NICU nurses, also the study results not in accordance with a study done in USA by Sekol and Kim who reported the nurses in the surgical unit had the lowest job satisfaction rather than the rest of studied units (hematology/oncology). From the researchers point of view in spite of no difference between the nurses in NICU and pediatric medical and surgical department satisfaction, nurses in departments have stable consistent environment than nurses in pediatric ICUS; where there are of unstable conditions, emergency situations, full working hours, and lack of rest. In study done in Iran add that the main sources of stress among nurses working in neonatal intensive care are the human factors ${ }^{[26]}$.

The study results illustrates no difference in performance between ICUS and departments nurses, these results contradicted with researchers expectations that "performance of NICU nurses are adequate than departments" because intensive care unit characterized by narrow span of control, clear role clarity and nurse patient ration, 1:1 all these factors could lead to satisfactory performance. Researches associate between better work environments and better nurse outcomes ${ }^{[27]}$. In Egyptian study concluded that clear job description, nurse patient ratio, availability of nurse aid, availability of training program, respectable relationship within the hospital staff make the work environment more conducive for work ${ }^{[24]}$.

The current study results indicated that bachelor nurses had high performance than diploma nurses; these results confirm findings by other researchers in a widely cited work of $\mathrm{Ng}$ and Feldman pointed out, the level of education is positively related to nurse's performance. Moreover, these findings consistent with American Association of Colleges of Nursing, which reported that nurses with Bachelor of Science in nursing degrees, are well-prepared to meet the needs of critical patients. Bachelor nurses are appreciated for their skills in critical thinking, leadership, and for their ability to practice across a variety of inpatient and outpatient settings.

The perceived initiation and consideration positively (leader behaviors) influenced job satisfaction and performance of staff nurses working in pediatric hospitals. In other words, the findings supported staff nurses working in pediatric hospitals significantly preferred the initiation leadership behavior over the consideration. 
Leadership Behaviors As Perceived By Pediatric Nurses and Its Effect on Their Satisfaction and ..

That is mean, they need more guidance, instructions, directions and they need to be more secure, as majority of them are working in critical units.

\section{Conclusion}

Pediatric nurses perceive the initiation behavior of their leadership more than consideration, positive correlation with highly statistically significant difference was detected between perceived head nurse behaviors, job satisfaction and performance of pediatric nurses, job satisfaction is higher among Egyptian, diploma and more than 5 years' experience nurses, while performance was higher among non-Egyptian and bachelor degree nurses with highly statistically significant differences.

\section{Recommendations}

The study recommends that pediatric nurses needs more supportive and enthiastic environment by their supervisors to attain her different roles with satisfaction and efficient performance. Also pediatric nurses need in-service training program to enhance their performance, the study highlights the need for replication in other settings; other variables relevant to job satisfaction and performance such as life stressors.

\section{References}

[1]. Sekol M., Kim S.," Job satisfaction, burnout, and stress among pediatric nurses in various specialty units at an acute care hospital. Journal of Nursing Education and Practice, 2014, Vol. 4, No. 12, 115-124.

[2]. Hockenberry, M. J., and Wilson, D. (2013): Wong's Nursing care of infants and children $9^{\text {th }}$. ed., The CV Mosby Company: Canada , pp.2,13-14.

[3]. Bahalkani,H., Kumar,R., Lakho, A., Mahar,B., Mazhar S. , Abdul Majeed," Job Sstisfaction in Nurses Working in Tertiary Health Care Settings of Islamabad, Pakistan ". Health Services Academy, Institute of Medical Sciences. J, Ayub Med Coll Abbottabad 2011;23(3), PP.130-133.

[4]. Belias D., \& Koustelios A., Leadership and Job satisfaction- A Review. European Scientific Journal, 2014, Vol.10, No.8, 24-46.

[5]. Frankel, A. What leadership styles should senior nurses develop? Nursing Times, 2011; 104: 35, 23-24.

[6]. Brady G, Cummings G." The influence of nursing leadership on nurse performance: a systematic literature review" journal nurse management,2010;18(4):425-39. doi: 10.1111/j.1365-2834.2010.01100.x

[7]. Roberts-Turner R., Hinds P., Nelson J., Pryor J., Robinson, N., Wang, J. Effects of Leadership Characteristics on Pediatric Registered Nurses' Job Satisfaction". Pediatr Nurs. 2014;40(5):236-241.

[8]. Northouse, P. G. (2013). Leadership: Theory and Practice, (6th ed). Sage Publications, Inc.

[9]. Malik, S. H. Relationship between Leader Behaviors and Employees' Job Satisfaction: A Path-Goal Approach. Pak J Commer Soc Sci Pakistan Journal of Commerce and Social Sciences 2013, Vol. 7 (1), 209-222

[10]. Daft, R.L. (2005). The Leadership Experience $3^{\text {rd }}$. Edition. Thomson-Southwestern, Vancouver.

[11]. Halpin, A.W. and Winer, B.J. (1957). A factorial study of the leader behavior descriptions. In R.M. Stogdill and A.E. Coons (eds), Leader behavior: Its description and measurement. Columbus, OH: Bureau of Buisness Research, Ohio State University.

[12]. Lawrence, P.G. (2007). Neohumility/Humility and Business Leadership: Do they belong together? Economics and Management, University of Minnesota, Morris.

[13]. Cox, K.S., Teasley, S.L., Lacey, S.R., Carroll, C.A., \& Sexton, K.A. Work environment perception of pedantic nurses. Journal of Pediatric Nursing, 2007, 22(1), 9-14.

[14]. Alloubani, A., Almatari, M., Almukhtar,M., REVIEW: Effects of Leadership Styles on Quality of Services in HealthCare. European Scientific Journal, 2014, Vol.10, No.18 ISSN: 1857 - 7881.

[15]. Fleishman, E.A. A leader behavior description for industry. In R.M. Stogdill, and A.E. Coons (Eds.), Leader Behavior: Its Description and Measurement, Columbus: The Ohio State University, Bureau of Business Research, 1957, Monograph No. 88.

[16]. Weiss, D. J., Dawis, R. V., England, G. W., \& Lofquist, L. H. (1967). Manual for the Minnesota Satisfaction Questionnaire. Minneapolis: University of Minnesota, Industrial Relation Center

[17]. Platis C.H., Reklitis P. \& Zimeras S. "Relation between job satisfaction and job performance in healthcare services, Procedia-Social and Behavioral Sciences, 2015, 175, 480-487.

[18]. Al-Ahmadi, H. "Factors affecting performance of hospital nurses in Riyadh Region, Saudi Arabia", International Journal of Health Care Quality Assurance, 2009, Vol. 22 Iss 1, pp. $40-54$.

[19]. Said N., Nave F., and Matos F. The Quality of Working Life among Nurses in Pediatric Setting. Selection \& Peer-review under responsibility of the Conference Organization Committee, The European Proceedings of Social \& Behavioural Sciences, 2015, eISSN : 2357-1330

[20]. Ababneh, O., (2009) "The Impact of Leadership Styles and Leaders' Competencies on Employees' Job Satisfaction", Published Master of Human Resource Management, Universiti Utara Malaysia73.

[21]. Hairr DC, Salisbury H, Johannsson M, Redfern-Vance N. 'Nursing staffing and the relationship to job satisfaction and retention', Nursing Economics, 2014, vol. 32, no. 3, pp. 142-47.

[22]. Salanova M, Lorente L, Chambel MJ, Martinez IM. 'Linking transformational leadership to nurses' extra-role performance: the mediating role of self-efficacy and work engagement', Journal of Advanced Nursing, 2011, vol. 67, no. 10, pp. 2256-2266.

[23]. DeRue, D. S., Nahrgang, J. D., Wellman, N., \& Humphrey, S. E. Trait and behavioral theories of leadership: An integration and meta-analytic test of their relative validity. Personnel Psychology, 2011, 64, 7-52.

[24]. Said R., Abed F., Abdo L., Work Motivating Factors as Identifed by Nurses in Children Hospital at Elmonira and Specialized Pediatric Hospital Cairo University. Med. J. Cairo Univ., 2013, vol. 81, No. 2, 27-31.

[25]. Ernst ME, Messmer PR, Franco M, Gonzalez JL. Nurses' job satisfaction, stress, and recognition in a pediatric setting, pediatric nurse, 2004;30(3):219-27.

[26]. Valizadeh, L., Farnam, A. Zamanzadeh, V., Bafandehzendeh, M. Sources of Stress for Nurses in Neonatal Intensive Care Units of East Azerbaijan Province, Iran. Journal of Caring Sciences, 2012, 1(4), 245-254

[27]. Liu K, You LM, Chen SX, Hao YT, Zhu XW, Zhang LF \& Aiken LH. The Relationship Between Hospital Work Environment and Nurse Outcomes in Guangdong, China: A Nurse Questionnaire Survey. Journal of Clinical Nursing, 2011, 21, 1476-1485. doi:10.1111/j.1365 2702.2011.03991. 
Leadership Behaviors As Perceived By Pediatric Nurses and Its Effect on Their Satisfaction and ..

[28]. Ng, T.W.H. \& Feldman, D.C. Organizational Tenure and Job Performance. Journal of Management, 2010, vol. 36 (5), pp 12201250

[29]. American Association of Colleges of Nursing, (2015), "The Impact of Education on Nursing Practice". Available at http://www.aacn.nche.edu/media-relations/fact-sheets/impact-of-education. Accessed at 18/8/2016. 